\title{
RELAÇÃO ENTRE EMPREGABILIDADE E FLEXIBILIZAÇÃO DA JORNADA DE TRABALHO
}

\section{RELATIONSHIP BETWEEN EMPLOYABILITY AND FLEXIBILIZATION OF THE WORK JOURNEY}

\author{
${ }^{1}$ Iana Melo Solano Dantas \\ ${ }^{2}$ Maria Aurea Baroni Cecato
}

\section{RESUMO}

Este artigo objetiva analisar a possibilidade de aumento da empregabilidade através da redução da duração do trabalho, com base na discussão acerca da necessária imposição de limites à flexibilização da jornada laboral. Nesse intento, analisaram-se: uma teoria formulada por Pastore (2009) que tenta provar essa relação, além das perspectivas legislativas sobre a matéria, concluindo-se que tais medidas, sozinhas, são insuficientes para criar novos postos formais de emprego. Sendo assim, consideraram-se relevantes e foram abordados, dois mecanismos limitadores da flexibilização. O método utilizado é o dedutivo em uma abordagem conceitual e teórico-normativa.

Palavras-chave: Jornada de trabalho, Redução, Emprego, Flexibilização

\begin{abstract}
This paper aims at examining the possibility of increasing the employability through reduction of the work journey, from the discussion about the necessary imposition of limits to the flexibilization of the working journey. In this regard, one considered a theory formulated by Pastore (2009), trying to verify that relationship, besides the legislative perspectives around that matter, and concluded that such measures, by themselves, are not sufficient to create new formal workplaces. Therefore, two limiting mechanisms of flexibilization are proposed. In this paper, one applies the deductive method, following conceptual and theoretical-normative approaches.
\end{abstract}

Keywords: Work journey, Reduction, Employment, Flexibilization

\footnotetext{
${ }^{1}$ Mestranda do Programa de Pós-Graduação em Ciências Jurídicas da Universidade Federal da Paraíba - PPGCJUFPB, Paraíba (Brasil). Professora da Universidade Federal de Campina Grande - UFCG, Paraíba (Brasil). E-mail: ianasolano@yahoo.com.br

${ }^{2}$ Doutora em Direito do Trabalho pela Université de Paris II, Panthéon-Assas (França). Professora Universidade Federal de Campina Grande - UFCG- UNIPÊ, Paraíba (Brasil). Professora Colaboradora da Universidade Federal da Paraíba, Paraíba (Brasil). E-mail: mariaaurea.cecato@gmail.com
} 


\section{INTRODUÇÃO}

Considerando o início da industrialização, marcada pela Revolução Industrial, em meados do século XVIII, percebe-se que a redução da duração do trabalho sempre esteve entre as principais reivindicações dos trabalhadores. Com efeito, ao lado da luta por melhores salários sempre registraram as demandas por jornadas menos extensas e mais suportáveis.

No final do século XX, quando o principal problema encontrado nas economias desenvolvidas passa a ser o desemprego, a discussão em torno da redução da jornada de trabalho adquire novo significado. Diferentemente dos séculos anteriores, quando a diminuição do tempo de trabalho visava principalmente à melhoria da qualidade de vida dos trabalhadores, agora ela adquire uma dimensão mais macroeconômica. A redução da jornada de trabalho volta ao centro do debate como instrumento de geração de novos postos de trabalho.

O debate sobre o combate ao desemprego resta polarizado. De um lado encontram-se aqueles que percebem que o referido combate carece de ações mais voltadas aos aspectos macroeconômicos, quer estruturais, quer conjunturais, e que a solução do problema viria pela adoção de políticas macroeconômicas capazes de aquecer a economia através de gastos públicos e/ou de políticas monetárias aptas a estimular os investimentos; de outro, os que entendem que o combate ao desemprego deve restringir-se a ações corretivas junto ao mercado de trabalho.

Para os que crêem que o problema se restringe ao âmbito microeconômico, atribuído a desequilíbrios no mercado de trabalho, a solução do desemprego seria a liberalização do mercado através da flexibilização e da desregulamentação do direito do trabalho. Como parte da mesma polêmica, em busca de formas de combate ao desemprego, formou-se uma discussão específica em torno da redução da jornada de trabalho.

Nesse quadro, este artigo objetiva analisar a possibilidade de aumento da empregabilidade através da redução da jornada de trabalho, contanto, todavia, como a imposição de limites à flexibilização da duração do trabalho. Ele não tem, entretanto, a pretensão de provar a relação direta entre a redução da jornada de trabalho e a geração de mais postos de trabalho, mas de contribuir para a verificação dessa possibilidade.

Destarte, o problema relativo à proposta pode ser assim formulado: A redução da jornada de trabalho pode ser utilizada como mecanismo apto a corroborar o aumento da empregabilidade? Como hipótese, aventa-se resposta afirmativa sobre a possibilidade do 
aumento do número de postos de trabalho a partir da redução da jornada de trabalho, desde que sejam impostos limites claros à flexibilização da jornada dessa jornada.

O método utilizado é o dedutivo, que numa cadeia de raciocínios em conexão descendente avaliará o instituto da flexibilização, afunilando a investigação para o ponto específico da flexibilização da jornada de trabalho, traçando a importância e as limitações necessárias à utilização da mesma como instrumento que poderá fomentar a empregabilidade a partir da redução da jornada de trabalho.

No tocante aos métodos de procedimento, utilizar-se-á o método hermenêutico para melhor interpretação dos documentos e legislações pertinentes dispostos no ordenamento jurídico brasileiro, estabelecendo análise comparativa e sistemática dos dispositivos da CF e da Consolidação das Leis Trabalhistas - CLT; dos tratados e convenções internacionais da matéria, bem como dos projetos de emenda constitucionais e medidas provisórias pertinentes ao objeto do presente estudo.

\section{UMA TEORIA SOBRE JORNADA DE TRABALHO E EMPREGO}

O crescimento da produtividade do trabalho, independentemente de suas causas, gera a diminuição do trabalho socialmente necessário. Essa diminuição pode se transformar em desemprego, criando um grave problema social, ou em diminuição da jornada de trabalho, conformando uma nova sociedade, onde todos terão, simultaneamente, tanto a garantia do trabalho quanto a certeza de mais tempo livre. Essas duas alternativas possíveis são construídas pela sociedade como resultado da luta de classes pela distribuição da renda e pelo controle do tempo do trabalhador, principalmente a partir do final do século $\mathrm{XX}$, quando o aumento do desemprego conferiu um novo significado à discussão sobre a redução da jornada de trabalho. ${ }^{1}$

A propósito da redução da carga horária, Pastore (2009, p. 88) elabora teoria que fundamenta essa pretensão e que se baseia nos seguintes argumentos:

\footnotetext{
${ }^{1}$ Nesse contexto, há muitos anos que as centrais sindicais do Brasil pleiteiam uma diminuição da jornada semanal estabelecida na Constituição Federal, pretendendo, com isso, melhorar a qualidade de vida dos trabalhadores e assegurar oportunidades de trabalho para todos.
} 
1. Ao estabelecer uma jornada legal de 40 horas semanais e um valor mínimo da hora extra em $75 \%$ da hora normal, as empresas empregarão um adicional de empregados para produzir o que estavam produzindo em 44 horas;

2. O aumento do custo da hora trabalhada (provocado pela redução de quatro horas e manutenção do mesmo salário) não afetará a vida das empresas;

3. O adicional de custo será compensado por um aumento da produtividade, garantido por empregados mais descansados, mais motivados e mais eficientes;

4. Graças ao aumento da produtividade, a empresa terá melhores condições de competir (com sucesso) no mercado nacional e internacional;

5. Do lado dos empregados, o aumento da produtividade permitirá a sua maior participação na renda gerada pelas empresas;

6. O aumento de renda propiciará um aumento do consumo, uma elevação da demanda e um estímulo para produzir mais;

7. O aumento da produção gerará mais empregos, formando-se, assim, o tão desejado círculo virtuoso;

8. Conclusão: a redução da jornada legal funcionará como um redutor do desemprego e estimulador do crescimento econômico e do progresso social;

A ideia por trás desse raciocínio é simples: o insumo trabalho na função de produção é dado pelo número de trabalhadores multiplicado pela jornada média de trabalho. Assim, se a jornada média diminui, o número de trabalhadores aumenta e a produção não se altera. Por exemplo, quatro pedreiros constroem uma parede trabalhando cada um dez horas por dia, ou seja, o serviço precisa de quarenta horas de trabalho para ser realizado. Mas se cada pedreiro trabalhar menos, imaginem-se 8 horas, o serviço será realizado da mesma maneira com mais um profissional, totalizando cinco pedreiros. A questão é saber se a substituição entre horas trabalhadas e emprego acontece dessa forma direta e se há viabilidade econômica das empresas, haja vista o possível aumento dos custos.

A teoria fundamenta-se, também, nos cálculos do Departamento Intersindical de Estatísticas e Estudos Socioeconômicos - DIEESE (2007, p. 5), segundo o qual a redução da jornada de trabalho de 44 para 40 horas semanais teria o impacto potencial de gerar em torno de 2.252.600 novos postos de trabalho no país.

Apesar desta estimativa, até mesmo Pastore (2009, p. 99) ressalta que os próprios defensores da redução da jornada defendem que a economia não é estática e que as empresas tendem a compensar a elevação de custo da redução da jornada, intensificando o trabalho dos empregados existentes, introduzindo tecnologias que poupam mão de obra ou ajustando a produção às novas condições de trabalho. Por isso, a simples regra de três não tem condições de gerar mais empregos.

Além disso, afirma que embora haja um aumento na produtividade, tal aumento não seria capaz de superar os custos advindos de novas contratações, sugerindo, ao final, que a redução da jornada de trabalho seja feita através de negociação coletiva, vislumbrando, nesses termos, a necessidade de diferenciação entre a redução da jornada legal e a redução da jornada 
negociada, acreditando ser essa última mais flexível e, portanto, de mais fácil adequação aos diversos setores, categorias e profissões.

Para potencializar a geração de novos postos de trabalho, esta pesquisa sugere, então, que a redução da jornada de trabalho seja acompanhada de outras medidas, como uma nova regulamentação do banco de horas e das horas extraordinárias, de modo que não se permita aos empresários compensar os efeitos de uma jornada menor de outra forma que não com a contratação de novos trabalhadores. ${ }^{2}$

\section{AS TRÊS DIMENSÕES DO PROBLEMA: O EMPREGADOR, A ECONOMIA NACIONAL E O EMPREGADO}

$\mathrm{Na}$ sociedade, quando se põe em pauta a discussão sobre a redução da jornada de trabalho pode-se observar o surgimento de interpretações antagônicas em três dimensões diferentes, sob o prisma da visão do empregador, da economia nacional e do empregado. A análise dessas interpretações é complexa em virtude dos interesses divergentes e comuns que circundam a relação que os unem, tornando necessário o seu registro.

Sob o prisma dos empresários, esses se colocam contra a ideia de redução da jornada de trabalho sem redução salarial, por vislumbrarem, desde logo, aumento de custos para as empresas. Nessa linha de raciocínio, cumpre desmistificar o custo social atribuído ao trabalho, na medida em que os níveis de desemprego são muito mais suscetíveis às variáveis macroeconômicas (juros, tributação, câmbio, poupança) do que necessariamente à rigidez da legislação trabalhista. Dessa forma, os trabalhadores passam a sofrer sérias e constantes perdas de seus direitos, até mesmo indisponíveis, sob o rótulo da flexibilização, mas que na verdade correspondem à desregulamentação do Direito do Trabalho e mitigação de seus princípios basilares.

É primordial ressaltar que a responsabilidade das empresas, na seara desse discurso, não pode ser descartada. Não só se deve exigir que o Estado assuma um papel de protetor do equilíbrio social e econômico, como também é importante que as empresas continuem produzindo riquezas, mas atentando para a responsabilidade social. A mínima proteção não é só função unilateral do Estado. É, também, responsabilidade das organizações econômicas o trabalho equilibrado e digno. É obrigação social e um dever. (YUNUS, 2008, p. 60)

\footnotetext{
${ }^{2}$ A questão será, adiante, objeto de exame mais detalhado.
} 
Em relação ao país, a redução da duração da jornada parece ser capaz de diminuir o desemprego (através da criação de novos postos de trabalho); aumentar a produtividade e competitividade diminuir os gastos sociais e aumentar a arrecadação, o que contribuiria para o crescimento econômico (PASTORE, 2009, p. 101).

Do ponto de vista dos trabalhadores, ao contrário do que possa parecer, a redução da jornada de trabalho, dependendo das condições em que ela for realizada, não é aceita de forma unânime. É evidente que a simples redução da jornada sem nenhuma contrapartida aos trabalhadores, no sentido de perda salarial, melhora a qualidade de vida dos mesmos. Porém, se em troca da redução da jornada os trabalhadores tiverem que aceitar redução dos salários ou até mesmo controle e diminuição das horas extras que signifique redução da remuneração pode haver descontentamento de alguns, principalmente dos trabalhadores de mais baixa renda.

No que se refere à voluntariedade na prestação de horas extras, por parte do trabalhador, com o intuito de aumentar sua remuneração, é preciso destacar que o instituto das horas extraordinárias foi criado para atender a situações excepcionais, não se podendo tolerar que diariamente, por anos seguidos, o empregador continue exigindo do trabalhador a prestação de horas extras sem qualquer justificativa, impedindo-lhe de estar com sua família, de exercer seu direito fundamental ao lazer, ou de aprimorar-se mediante o estudo.

Defensor da redução da jornada de trabalho, Calvete (2006, p. 430) reconhece que essa medida não deverá caracterizar instrumento da precarização das condições de trabalho. Diminuição de salários, flexibilização do horário e perda de benefícios poderiam transformar a redução da jornada em uma extensão do emprego por tempo parcial. Como defende o autor, o que seria benéfico para a economia e para todos os agentes seria a manutenção das condições e benefícios do emprego através da redução da jornada, ou seja, com a manutenção do trabalho em tempo integral, porém com jornada menor.

No que diz respeito à saúde do trabalhador, a redução da jornada de trabalho mostrase como medida profilática importante no âmbito da medicina laboral, pois tende a diminuir a exposição a potenciais insalubres. Isso vai ao encontro do disposto no artigo $7^{\circ}, \mathrm{XXII}$ da Constituição Federal que prevê: “[...] redução dos riscos inerentes ao trabalho, por meio de normas de saúde, higiene e segurança”. Com efeito, uma carga horária excessiva pode provocar esgotamento mental e físico com consequente degradação qualitativa do desempenho do trabalho, podendo aumentar a ocorrência de acidentes e contribuindo para o aparecimento de distúrbios e lesões. Assim, a redução da jornada de trabalho de quarenta e 
quatro horas para quarenta horas semanais mostra-se como importante medida de saúde no ambiente de trabalho, pois amortizaria o desgaste intrínseco à atividade laborativa.

Com relação à educação do trabalhador, a redução da jornada de trabalho representaria a possibilidade de aproveitamento do tempo livre investindo em sua qualificação. No tocante à vida familiar, a redução da jornada proporcionaria maior tempo de dedicação aos filhos e demais dependentes. Isso colaboraria para a instituição da política pública de resgate da família na sociedade brasileira, o que possibilitaria melhor desempenho dos mecanismos que contribuem para a formação e socialização das crianças e jovens brasileiros (DELGADO, 2007, p. 28).

Por esses motivos, além da obrigatoriedade do Estado em zelar pela proteção da saúde, higiene e segurança do trabalhador (inciso XXII do artigo $7^{\circ}$ ), bem como a de cuidar da proteção do meio ambiente de trabalho, na interpretação conjunta do inciso XIII, do artigo 200 com o artigo 225 e parágrafos da CF é que se defende que, mesmo o trabalhador concordando com o trabalho em regime de horas extraordinárias, a redução das mesmas se faz premente, haja vista o bem maior que se está tentando preservar, a sua dignidade, que não raramente se vê vilipendiada por motivos meramente econômicos. Por isso, cumpre analisar a relação entre a redução da jornada de trabalho e o princípio da dignidade da pessoa humana, como se verá a seguir.

\section{REDUÇÃO DA DURAÇÃO DO TRABALHO COMO MECANISMO DE EFETIVAÇÃO DO PRINCÍPIO DA DIGNIDADE DA PESSOA HUMANA}

O ponto central da imperatividade do princípio da dignidade da pessoa humana está no fato de que a vida em sociedade somente terá sentido se ao indivíduo forem garantidos os seus direitos civis, políticos, sociais, econômicos e culturais.

Sob a égide do Estado Democrático de Direito, em 1988, foi promulgada a Carta Magna brasileira - a Constituição Cidadã - que traz, como princípio nuclear, a dignidade da pessoa humana; mais que um princípio é a razão de ser do Direito, como destaca Nery Jr. (2009, p. 151), ao discorrer que: "Esse princípio não é apenas uma arma de argumentação, ou uma tábua de salvação para a complementação de interpretações possíveis de normas postas. Ele é a razão de ser do Direito. Ele se bastaria sozinho para estruturar o sistema jurídico."

Sarlet (2011, p. 70) assevera que a Carta Magna "[...] reconheceu categoricamente que é o Estado que existe em função da pessoa humana, e não ao contrário, já que o ser 
humano constitui a finalidade precípua e não meio da atividade estatal." Segundo o autor, as prestações devem ser vinculadas à noção de mínimo existencial, abrangendo, “[...] o conjunto de prestações materiais que asseguram a cada indivíduo uma vida com dignidade" e "[...] a noção de um mínimo vital ou a uma noção estritamente liberal de um mínimo suficiente para assegurar o exercício das liberdades fundamentais."

Não há dúvidas e que é dever do Estado garantir o máximo possível de justiça social e, consequentemente, resguardar ao cidadão o conjunto de direitos humanos que, por sua vez, envolve uma série de direitos interligados, entre eles os direitos dos trabalhadores. Nesse sentido enfatiza Cecato (2007, p. 173):

\begin{abstract}
As conexões que se estabelecem entre direitos laborais e desenvolvimento passam, antes de tudo, pelos direitos econômicos e sociais, os quais, por sua vez, se firmam sobre os direitos civis e políticos e têm sua efetivação também assentada nos direitos de solidariedade e fraternidade. Estabelecem-se, portanto, no princípio da indivisibilidade dos direitos humanos e fundamentais, indivisibilidade essa aprendida na realidade e afirmada a partir da Declaração Universal dos Direitos Humanos (ONU, 1948), marco contemporâneo da sustentação da dignidade do ser humano.
\end{abstract}

Portanto, o trabalho está diretamente relacionado à dignidade da pessoa humana, uma vez que permite ao cidadão desenvolver perspectivas de melhoria de sua condição social e garantir a sua sobrevivência e a de sua família, enfim, de ter possibilidade de construir e realizar os seus sonhos. Nesse caso, a discussão em questão visa abordar a exploração do trabalho com jornadas que não permitam a fruição de todos os direitos consubstanciados no princípio da dignidade da pessoa humana.

Quando de trata da preservação da dignidade aborda-se um direito fundamental a ser resguardado pelo Estado e pela sociedade em geral. O empregado, enquanto criatura humana e sujeito de direitos deve ter garantia de tratamento com respeito e a certeza da promoção de sua dignidade. O problema quanto à efetiva garantia da dignidade do trabalhador surge com os conflitos de interesses das classes na relação de emprego na sociedade capitalista.

Oportuno obtemperar que problemas sociais e econômicos não podem, em hipótese alguma, servirem de argumento para o desrespeito aos direitos humanos fundamentais de qualquer ser humano, tampouco do trabalhador. A garantia dos direitos humanos fundamentais é inerente ao regime democrático; onde não se respeitam os direitos essenciais não se pode dizer que existe democracia plena.

É fato que as relações de trabalho se prestam às mais cruéis formas de exploração do ser humano, visando prioritariamente o lucro, que destroem a dignidade da pessoa humana. 
Corrobora com esse quadro, o processo da globalização econômica, especialmente no que diz respeito à produção, ao comércio e aos investimentos, atingindo forte e duramente os direitos laborais. O trabalho subserviente, terceirizado, informal e de escassas condições de dignidade, em geral, deixam o trabalhador cada vez mais à margem das regras da economia de mercado. O Estado, instado a se ausentar das relações capital-trabalho, enfrenta obstáculos na concorrência com outros atores do mundo das decisões e regulamentações. Aliás, poder-se-ia dizer, da desregulamentação (CECATO, 2008, p. 175).

Por outro lado, é na perspectiva da dignidade dos trabalhadores que a OIT Organização Internacional do Trabalho - busca a promoção universal do trabalho decente, estabelecendo uma agenda que contempla os preceitos da Declaração de 1998 sobre princípios e direitos fundamentais no trabalho, mas indo além, para alcançar os direitos dos trabalhadores: o emprego; a proteção social e o diálogo social. Dentro da preocupação com padrões morais e éticos, o trabalho decente se traduz no pleno desenvolvimento do trabalhador.

Nessa perspectiva, é importante garantir que os direitos que já foram conquistados a duras lutas, não sofram retrocesso. Nesse sentido, Sarlet (2011, p. 85) enfatiza a importância da figura da proibição do retrocesso na ordem jurídica constitucional e na segurança jurídica que ela deve assegurar, tendo em vista o Estado de Direito a que pertence. Barroso (2000, p. 152), referindo-se ao princípio da proibição do retrocesso, sustenta que, apesar desse princípio não estar expressamente previsto, ele "[...] decorre do sistema jurídico-constitucional, entende-se que se uma lei, ao regulamentar um mandamento constitucional, instituir determinado direito, ele se incorpora ao patrimônio jurídico da cidadania e não pode ser arbitrariamente suprimido".

Destarte, a redução da duração do trabalho sem redução de salários, com o objetivo de se chegar a jornadas justas com salários compensatórios pode ser um dos elementos para a efetivação do trabalho decente e da dignidade da pessoa humana, desde que complementada pelos demais direitos fundamentais do indivíduo, previstos na Carta Soberana. Ao concordarem com jornadas extensas realizando muitas horas suplementares, os empregados acabam consentindo com o aviltamento de seus direitos e, portanto, de sua própria dignidade, motivo pelo qual as atenções devem se voltar para mecanismo que impossibilite essa agressão. A redução da jornada de trabalho apresenta-se, portanto, como um desses mecanismos para atingir tal fim. 


\section{PERSPECTIVAS DE REDUÇÃO DA JORNADA DE TRABALHO NO ÂMBITO DO PODER LEGISLATIVO}

É certo que o tema redução da duração do trabalho é recorrente nas casas legislativas federais do Brasil, visto que, apesar de se ter admitido como padrão a duração diária de oito horas, muito ainda se discute quanto à possibilidade e, até, à necessidade de diminuição dessa carga horária.

Existem, atualmente, no Brasil, inúmeros Projetos em tramitação no Congresso Nacional, propondo a redução da duração do trabalho, desde projetos que visam apenas aos interesses de determinadas categorias de trabalhadores até aqueles que visam à redução da jornada padrão de trabalho.

Coadunam-se mais com o objeto da presente pesquisa, as proposta de emenda constitucional - PEC no 231/1995 e a PEC no 75/2003. A primeira, de autoria do deputado Inácio Arruda do PCdoB/CE, propõe a alteração dos incisos XIII e XVI do artigo $7^{\circ}$ da $\mathrm{CF}$, para que a duração máxima do trabalho passe para 40 horas semanais e aumente para 75 por cento a remuneração de serviço extraordinário. A segunda, de autoria do senador Paulo Paim do PT/RS, propõe a alteração do inciso XIII do artigo $7^{\circ}$ da CF para reduzir a duração do trabalho semanal de 44 para 36 horas, sendo que a duração diária continuaria com o limite de oito horas e também permaneceria a possibilidade de compensação de horários, mediante acordo ou convenção coletiva de trabalho.

Além disso, diante da crise por que vem passando a economia brasileira, associada ao aumento dos índices de desemprego, em 11 de novembro de 2015 foi publicada a Lei $\mathrm{n}^{\circ}$ 13.189 que cria o Programa de Proteção ao Emprego - PPE, através da redução da jornada de trabalho e salários em até $30 \%$. Os empregados que tiverem seu salário reduzido, nos termos da referida lei, farão jus a uma compensação pecuniária equivalente a $50 \%$ do valor da redução salarial e limitada a $65 \%$ do valor máximo da parcela do seguro-desemprego, enquanto perdurar o período de redução temporária da jornada de trabalho.

A lei ainda prevê que a forma de pagamento dessa compensação pecuniária será custeada pelo Fundo de Amparo ao Trabalhador - FAT e que o salário a ser pago - com recursos próprios do empregador - após a redução salarial tratada na lei, não poderá ser inferior ao valor de um salário mínimo.

Em termos práticos, quanto menos o empregado trabalhar, menos vai receber. Mas a diferença do salário será parcialmente compensada pelo governo, que vai pagar $50 \%$ da perda 
com o FAT. Essa compensação está limitada a R\$ 900,84, que corresponde a $65 \%$ do maior benefício do seguro-desemprego, que atualmente corresponde a $\mathrm{R} \$ 1.385,91$. $^{3}$

\section{LIMITES À FLEXIBILIZAÇÃO DA JORNADA DE TRABALHO}

A fixação da jornada de trabalho é questão basilar da ordem social, de modo que os direitos trabalhistas relacionados a tal matéria devem ser rigorosamente submetidos a um regime próprio imperativo, inalienável e irrenunciável pelos particulares. Os direitos aqui tratados são indisponíveis, assegurados pela própria Constituição Federal e que, por sua própria natureza gozam de mecanismos de proteção mais amplos e rígidos.

Entretanto, a Carta Magna adotou, em limitadas, mas relevantes hipóteses, a flexibilização de algumas de suas normas, quais sejam: redutibilidade salarial, compensação de horários e trabalho em turnos ininterruptos de revezamento (art. $7^{\circ}$, incisos VI, XIII e XVI). Tais matérias só poderão ser modificadas por meio de negociação sindical. Diante da norma permissiva constitucional, a aceitação da flexibilização da duração do trabalho vem se generalizando, quer na elaboração de normas legais e convencionais, quer na aplicação das mesmas.

A presente pesquisa busca enxergar a ideologia neoliberal que permeia o instituto da flexibilização das normas trabalhistas, discordando que o mesmo seja a solução para o desemprego e funcione como estimulador do desenvolvimento econômico. Nessa linha de raciocínio, a presente pesquisa acredita que a mera redução da jornada de trabalho com a aprovação da PEC n 231/1995, da no 75/2005 ou em decorrência da Lei nº 13.189ட2015 é insuficiente para a efetiva criação de novos postos de trabalho se não vier acompanhada da referida limitação da flexibilização da jornada de trabalho, consubstanciada através de controles mais rígidos no regime das horas extraordinárias e do bando de horas. Essas duas medidas serão objeto de análise nos tópicos seguintes.

\footnotetext{
${ }^{3}$ Em virtude de ter sido publicada recentemente, não pôde-se contabilizar os efeitos práticos da referida lei na diminuição dos índices de desemprego
} 


\subsection{A necessidade de efetiva limitação das horas extraordinárias}

As horas extraordinárias sempre constituíram forma de ultrapassar os limites de jornada, de permitir o trabalho além das horas normais. Assim, é claramente de natureza excepcional, razão pela qual pode-se asserir ser incongruente admitir que, enquanto hora extraordinária, possa se tornar habitual.

A OIT constata que há vantagens e desvantagens na realização de horas extras. As primeiras ocorrem porque ao empregador é muito conveniente exigir a realização regular e sistemática de horas extraordinárias, entre tantos motivos, porque a concentração de mais trabalhadores para fazer frente à demanda sempre importa no aumento dos encargos sociais e de outros custos não salariais. Para o trabalhador também há uma motivação puramente econômica, posto que nos países em que as horas extraordinárias são largamente permitidas, os pagamentos correspondentes terminam por fazer parte da remuneração regular, de forma que os próprios trabalhadores tenham interesse em prestá-las (SILVA, 2013, p. 171).

No entanto, a aparente vantagem pode se tornar muito prejudicial aos trabalhadores que constantemente cumprem horas extraordinárias. Tal prática resulta no aumento da fadiga e da tensão no trabalho, cujas consequências mais graves podem ser a perda, ainda que temporária, da saúde e segurança dos trabalhadores.

No Brasil, ainda que sejam normas de eficácia plena as dos incisos XIII e XIV do artigo $7^{\circ}$ da $\mathrm{CF}$, tem havido uma prática abusiva de horas extras que retira todo o efeito de proteção destas normas, motivo pelo qual não se entende a omissão do Estado brasileiro no que se refere à prestação de horas extras habituais.

Nem se objete que o inciso XVI do artigo $7^{\circ}$ autoriza a prestação de horas extraordinárias sem limites no Brasil, até porque o Estado brasileiro tem várias obrigações no que concerne à proteção da saúde, higiene e segurança (inciso XXII do artigo $7^{\circ}$ ), bem como a de cuidar da proteção do meio ambiente de trabalho, na interpretação conjunta do inciso XIII, do artigo 200 com o artigo 225 e parágrafos da CF. De modo que não se pode exigir horas extraordinárias habituais dos trabalhadores brasileiros, pois foi permitida de maneira ordinária apenas a compensação de horários, e somente no horário fixo e não nos turnos interruptos de revezamento (interpretação sistemática dos incisos XIII e XIV do artigo $7^{\circ}$ da CF).

Numa interpretação lógica e sistemática do artigo 61 e parágrafos da CLT, pode-se chegar à conclusão de que o legislador brasileiro se preocupou em definir parâmetros a fim de 
que o serviço extraordinário tivesse limites objetivos, levando em conta que a limitação efetiva da jornada de trabalho não pode conviver com horas extraordinárias sem limite.

Não obstante a incontestabilidade de todos os fundamentos expendidos anteriormente, a realização de trabalho além do limite fixado pelas normas constitucionais, por lei ou por convenções e acordos coletivos de trabalho, tem sido um fato rotineiro no Brasil.

Sem embargo, essa violação dos limites de jornada tem sido uma prática diuturna, com o beneplácito dos sindicatos, dos auditores fiscais do trabalho e, por que não, da própria Justiça do Trabalho, tanto que esta criou a tese da sobrejornada habitual para efeito de pagamento de reflexos de horas extras, fortalecendo, mesmo que indiretamente, essa prática (Súmula 347 do TST). Verifica-se, portanto, uma cultura nacional de prestação de horas extras, o que justifica e, mesmo, demanda a proposta de limites à referida prática.

Ideal seria a sistemática proibição à realização de sobrejornada. Não obstante, em casos excepcionais não há como proibir a exigência de horas extras por parte do empregado, tanto que o legislador brasileiro, sensível aos casos de necessidade imperiosa, regulamentou a matéria no citado artigo 61 da CLT.

Por outro lado, não se pode tolerar que diariamente, por anos seguidos, o empregador continue exigindo dos trabalhadores a prestação de horas extras sem qualquer justificativa, impedindo-lhes de estar com suas famílias, de exercer o direito fundamental ao lazer, ou de aprimorar-se mediante o estudo, garantindo-lhes o desenvolvimento pessoal e, por conseguinte, contribuindo para a promoção da dignidade desses trabalhadores.

Com base numa pesquisa nacional realizada com trabalhadores de diversas categorias profissionais, a CUT - Central Única dos Trabalhadores (CUT BRASIL, 2006, p. 163) lançou proposta de limitação das horas extras, que implica em alteração do artigo 59 da CLT. A partir daí, o dispositivo legal deveria fixar os seguintes totais máximos de horas extras: a) duas horas extras por dia; b) 30 horas extras por mês; c) 110 horas extras por semestre. E explica a razão desses percentuais: a ideia é a de que as "quotas máximas de horas extras" sejam proporcionalmente decrescentes ao logo de períodos maiores; assim, se a jornada diária for de 7,33 horas (que corresponde à jornada semanal de 44 horas), a quota máxima de horas extras a ser permitida será de $27 \%$, ou seja, de duas horas diárias; se a jornada máxima mensal for de aproximadamente 183 horas, a quota máxima será de $16 \%$, isto é, de 30 horas extras por mês; se a jornada semestral for de 1.100 horas, a quota será de $10 \%$, ou de 110 horas extras por semestre. 
Importante registrar que do universo de trabalhadores entrevistados na referida pesquisa, $77,8 \%$ deles declararam trabalhar em horas extras, sendo que, deste total, $25 \%$ afirmaram prestar hora extra frequentemente. E, a se considerar os trabalhadores informais, os quais normalmente não têm qualquer limite de jornada de trabalho, esses números seriam muito mais elevados (CUT BRASIL, 2006, p. 170).

Desse modo, poder-se-ia aferir que, se são tantas as dificuldades (econômica, cultural, política) para a total vedação das horas extraordinárias, há que se pensar em limitálas ao máximo, principalmente nas atividades repetitivas, nas quais o ritmo de trabalho é mais intenso e o efeito danoso que provocam na saúde dos trabalhadores é incontestável. Nesse aspecto, apresenta-se como salutar a majoração do adicional de horas extras para $75 \%$ preconizado na PEC no 231\1995.

Evidentemente, há que se pensar, ainda, que em havendo novas normas mais adequadas ao trabalho digno, ainda será imprescindível a participação de sindicatos e órgãos de fiscalização do trabalho atuando intensamente para que as novas regras sejam cumpridas.

\subsection{A extinção do banco de horas e a participação dos sindicatos}

A segunda medida limitadora da flexibilização da duração do trabalho proposta por essa pesquisa para que a redução da jornada de trabalho possa influenciar na criação de novos postos de trabalho, é a extinção do banco de horas, normatizado, atualmente, no $\S 2^{\circ}$ do artigo 59, da CLT. O argumento utilizado à época da criação do banco de horas era o de que não havendo o pagamento das horas extras prestadas nos períodos de incremento na produção seriam poupados empregos nas épocas de baixa produção pela possibilidade de concessão de folgas compensatórias.

$\mathrm{Na}$ verdade, com a instituição do banco de horas, "apenas concede-se ao empregador um prazo maior para quitar a dívida trabalhista constituída pelo trabalho extraordinário prestado pelo empregado, com o benefício, ainda, de não remunerar o adicional de hora extra" (RAMOS FILHO, 2012, p. 374).

Exatamente por ser considerada extraordinária a prestação de labor para além das horas normais contratualmente estabelecidas, a ordem jurídica sempre estabeleceu que os empregados não são obrigados a realizar horas extras, salvo nos casos previstos no artigo 61 da CLT. A doutrina majoritária sempre reconheceu que tais limitações impostas à liberdade contratual obedeceriam aos imperativos de ordem pública, como fator de preservação da 
saúde dos trabalhadores, diminuindo os gastos públicos para a recuperação dos trabalhadores enfermos pelo excesso de trabalho a que tenham sido submetidos. Contudo, de modo contraditório, sob a alegação da manutenção dos empregos, precarizam-se as garantias legais dos empregados sem exigência de qualquer garantia de emprego aos trabalhadores submetidos ao banco de horas.

A nova sistemática ampliou o prazo para a compensação do acréscimo de jornadas possibilitando que aquelas horas extras devidas juntamente com o salário, no início do mês seguinte, sejam quitadas em prazos superiores, mediante compensação e, portanto, sem o pagamento dos respectivos adicionais, sempre sob a justificativa da manutenção dos empregos.

Nos primeiros anos após a inovação legislativa, alguns sindicatos iniciaram processos de resistência, quando instados pelas empresas a firmar acordos para implementação do banco de horas, condicionando a sua concordância à aceitação por parte dos empregadores da garantia de emprego pelo prazo de sua vigência.

$\mathrm{O}$ argumento utilizado à época resgatava o discurso empresarial: se as empresas queriam instituir o banco de horas para deixar de pagar as horas extras nos períodos de aumento da produção com o objetivo de evitar demissões nas épocas de menor produtividade, compensando as horas extras não pagas com folgas posteriores, alguns sindicatos passaram a exigir que os empregos fossem formalmente mantidos durante o prazo de vigência dos acordos que instituíam o banco de horas.

Todavia, nos anos seguintes, pouco a pouco, esses processos de resistência foram perdendo força em face da incompreensão por parte dos próprios trabalhadores, que, convencidos pelos empregadores, passaram a considerar tais posturas sindicais como anacrônicas e em descompasso com a ambiência histórica de então (RAMOS FILHO, 2012, p. 375).

Assim, esse forte instrumento de flexibilização da jornada de trabalho - o banco de horas ou a anualização da jornada de trabalho (epíteto também utilizado por alguns doutrinadores) atenta contra a finalidade nuclear da normativa sobre a matéria, que para além do fomento ao emprego, consubstancia-se na devida proteção à segurança e à saúde dos trabalhadores.

E ainda mais, a distribuição irregular da jornada de trabalho, por meio do mecanismo do banco de horas, sem uma previsão de causas justificadoras, limites efetivos à distribuição dos horários, situações objetivas para que se proceda ao descanso compensatório, configura-se 
numa agressão não só à saúde e segurança, mas a todos os direitos fundamentais dos trabalhadores.

Destarte, a redução da jornada de trabalho somente poderá contribuir para o aumento dos postos de trabalho se a hora extraordinária ficar efetivamente inviável para o empregador e, paralelamente, vedar-se em definitivo a compensação de horários por meio do banco de horas.

Portanto, além da alteração do inciso XIII do artigo $7^{\circ}$ da $\mathrm{CF}$, a proposta deverá abranger inclusive a alteração ao inciso XVI do mesmo artigo. Também será necessária a revogação do $\S 2^{\circ}$ do artigo 59 da CLT, que prevê o banco de horas, com supressão do adicional de horas extras, além da aprovação da PEC n 231 1995 , que prevê a redução da jornada de trabalho de 44 para 40 horas semanais e o aumento do valor das horas extraordinárias para 75 por cento.

Diante dos argumentos levantados no decorrer desse trabalho, acredita-se haver uma tendência de que se a duração do trabalho for reduzida com restrições severas à realização de horas extraordinárias e ao banco de horas, haverá necessidade de uma maior massa trabalhadora para manter a produção nos patamares atuais.

Em contrapartida, para atender a este objetivo, qual seja, aumentar a empregabilidade e consequentemente promover a paz social por meio da garantia do direito social ao trabalho, é imprescindível a participação efetiva de sindicatos fortes, com reais poderes representativos, pois somente a força coletiva poderá sustentar tais mudanças, perante os embates que envolvem o tema.

Nessa linha de raciocínio, deve-se reconhecer a crise por que passa o setor sindical atualmente. O novo desafio dos sindicatos passou a ser como aglutinar trabalhadores cada vez mais dispersos e precários em projetos políticos e sindicais comuns, num contexto em que a globalização e a inovação reduzem continuamente a capacidade de manobra de Estados e dos próprios sindicatos (DUPAS, 1999, p. 14).

$\mathrm{Na}$ atual conjuntura do movimento sindical, o traço mais marcante nos diversos países tem sido o da defensividade sindical, na medida em que as transformações operadas pelo modo de produção capitalista, sobretudo nas últimas décadas, impulsionavam o campo de trabalho para a adoção de ações mais defensivas que ofensivas, isto é, muito mais direcionadas à manutenção de antigas conquistas do que ao estabelecimento de novas, com conseqüente ampliação dos direitos sociais para o trabalho ( MÉSZÁROS, 2006, p. 31). 
Para contornar essa situação, há que haver sindicatos fortes, com reais poderes de representatividade, o que, em tese, garantiria a observância do princípio protetor e da dignidade do trabalhador. No caso do Brasil, a democratização do sistema sindical só ocorrerá através de delicada transição que altere os matizes corporativistas e interventores da década de 1930, mas que mantêm-se preservados pela Constituição de 1988, estorvando o exercício da sindicalização livre e suas implicações no que diz respeito à defesa dos direitos coletivos dos trabalhadores. Aludida transição, perpassa, obrigatoriamente, pela ratificação da Convenção $\mathrm{n}^{\circ}$ 87, da OIT, documento de índole internacional, que encerra as regras e princípios da liberdade sindical. A sua ratificação, adequaria o Brasil ao sistema de liberdades e de respeito às liberdades civis de associação, próprias de um Estado Democrático de Direito.

Contudo, o que se percebe quanto ao aspecto empregabilidade, em virtude da redução da duração do trabalho, é que há uma patente necessidade de evolução cultural, que culmine na conscientização dos atores sociais (empregados, empregadores, sindicatos e Estado) de que a redução da duração do trabalho pode beneficiar, em vários aspectos, a sociedade em geral, desde que planejada de modo a atender os interesses de todas as partes.

\section{CONCLUSÃO}

Tem-se, hodiernamente, considerável aumento da preocupação com o desemprego, em face do avanço tecnológico e crescimento populacional, fatos que levaram essa pesquisa à formulação do questionamento sobre a possibilidade de contribuição da redução da duração do trabalho para o aumento de postos de trabalho formais.

O ordenamento jurídico brasileiro, por sua vez, além de contemplar a duração semanal do trabalho em 44 horas, trouxe possibilidades de flexibilização, como a compensação semanal e anual de horários. Nesse aspecto, observou-se que a flexibilização enquanto instrumento criado pela montagem de um suposto pensamento único da hegemonia do modelo neoliberal, como solução para os problemas econômicos, dos quais não se aparta o desemprego, pode ser causadora da ausência de postos de trabalho formais ou da precarização dos empregos restantes.

Percebeu-se que dentre as várias propostas que tramitam no Congresso Nacional, visando à redução da duração do trabalho no Brasil, a mais consistente e de abrangência geral é a PEC $n^{\circ} 231 / 95$, que prevê a redução da duração semanal de trabalho de 44 para 40 horas, além do aumento do adicional de horas extraordinários de $50 \%$ para, no mínimo $75 \%$. 
Apresentou-se, também, uma teoria formulada por Pastore (2009), que faz uma relação entre a redução da duração do trabalho e o aumento da empregabilidade. Entretanto, constatou-se, a partir da análise de suas variantes, que a mesma, sozinha, é insuficiente para efetivamente criar novos postos de trabalho formal. As empresas têm vários instrumentos para compensar a redução da jornada de trabalho sem necessitar a admissão de novos empregados. Em geral, esta é, de fato, a última alternativa por elas adotada. Em momentos de redução da jornada de trabalho imposta por leis sem levar em conta alguma obrigatoriedade ou contrapartida para a contratação, muitas empresas optam pela introdução de novas tecnologias, sejam elas de automação ou de novas técnicas organizacionais. Estas introduções muitas vezes tornam desnecessárias novas contratações.

Demais disso, a criação do chamado banco de horas contribuiu, sobremaneira, para utilização de horas suplementares de trabalho pelo empregador, posto que possibilitou a própria supressão do adicional de horas extras. Destarte, percebe-se que o encarecimento das horas extraordinárias de trabalho foi mitigado pela possibilidade de compensação de horários, sem o pagamento do referido adicional.

A presente pesquisa propugna que se a duração do trabalho for reduzida impondo limites à flexibilização da jornada de trabalho, através de severas restrições à realização de horas extraordinárias, e vedando-se em definitivo a compensação de horários por meio do banco de horas, haverá necessidade de maior massa trabalhadora para manter a produção nos patamares atuais.

Em contrapartida, se o objetivo é aumentar a empregabilidade e consequentemente promover a paz social por meio da garantia do direito social ao trabalho, é imprescindível que o Estado promova a implantação de políticas públicas no sentido de diminuir a carga tributária, investir em infraestrutura, eficiência administrativa, educação, tecnologia, entre outros.

Para tanto, há ainda a necessidade de modernização das estruturas sindicais, que, em plena Revolução Tecnológica, precisam se desvencilhar do modelo arcaico, preso às fábricas, e atuar de forma mais tecnológica, a fim de congregar a grande massa de trabalhadores do setor tecnológico e de fortalecer as sua bases através de um cariz mais ofensivo que defensivo, restabelecendo a utopia atrelada aos movimentos sindicais.

A questão primordial, contudo, reside na imprescindibilidade de uma efetiva mudança de pensamento, quanto aos valores almejados pelo capitalismo, indo de encontro à 
racionalidade econômica que nos é imposta. A redução da duração do trabalho possibilitaria ao empregado viver com dignidade os demais momentos de sua vida fora do ambiente laboral.

Este é o momento de se retomar o pensamento do papa Leão XIII na Encíclica Rerum Novarum. Afinal, o trabalhador insatisfeito, estressado, cansado ou doente, assim como uma massa de trabalhadores desempregados, formam um conjunto de situações com consequências nefastas à sociedade em geral; muito mais do que o custo de produção, o que está em discussão é a busca pela paz, pela justiça social e pela dignidade do trabalhador.

\section{REFERÊNCIAS}

BARROSO, Luís Roberto. $O$ direito constitucional e a efetividade de suas normas. $3^{\mathrm{a}}$ ed. Rio de Janeiro: Renovar, 2000.

CALVETE, Cássio da Silva. A redução da jornada de trabalho como solução do desemprego: o mito de Sísifo ou Prometeu? Civitas, Porto Alegre, v. 3, n. 2, 2003, p. 417-433, jul.-dez.

Disponível em: http://revistaseletronicas.pucrs.br/ojs/ index.php/civitas/article/viewFile/128/ 123. Acesso em: 5.mar.2015.

. 2006. Redução da jornada de trabalho: uma análise econômica para o Brasil. Campinas. Tese (Doutorado em Economia). Universidade Estadual de Campinas, 2006.

CECATO, Maria Áurea Baroni. Direitos laborais e desenvolvimento: interconexões. Boletim de Ciências Econômicas, v. LI, 2008.

Direitos humanos do trabalhador: para além da Declaração de 1998 da OIT, In: Rosa M. Godoy Silveira et alii, Educação em direitos humanos: fundamentos teóricometodológicos. João Pessoa: Editora Universitária, 2007.

CUT. Hora extra: o que a CUT tem a dizer sobre isto. Secretaria de Política Sindical da CUT. São Paulo: CUT Brasil, 2006.

DELGADO, Maurício Godinho. Capitalismo, trabalho e emprego: entre o paradigma da destruição e os caminhos da reconstrução. São Paulo: LTr, 2007.

DIEESE. Argumentos para a discussão da redução da jornada de trabalho no Brasil sem redução do salário. Nota técnica 66, 2007.

DUPAS, Gilberto. Economia global e exclusão social: pobreza, emprego, Estado e o futuro do capitalismo. $2^{\text {a }}$ ed. Rio de Janeiro: Paz e Terra, 1999.

MÉSZÁROS, István. Desemprego e precarização: um grande desafio para a esquerda. In:

ANTUNES, R. (Org.) Riqueza e miséria do trabalho no Brasil. São Paulo: Boitempo, 2006. 
NERY JUNIOR, Nelson; NERY, Rosa Maria de Andrade. Constituição Federal comentada e legislação constitucional. $2^{\text {a }}$ ed. São Paulo: Revista dos Tribunais, 2009.

RAMOS FILHO, Wilson. Direito capitalista do trabalho: história, mitos e perspectivas no Brasil. São Paulo, LTr, 2012.

SARLET, Ingo Wolfgang. A eficácia dos Direitos Fundamentais. 10ª ed. Porto Alegre: Livraria do Advogado, 2011.

\section{Dignidade da pessoa humana e direitos fundamentais na Constituição Federal}

de 1988. $9^{\mathrm{a}}$ ed. Porto Alegre: Livraria do Advogado, 2011.

SILVA, José Antônio Ribeiro de Oliveira. A flexibilização da jornada de trabalho e a violação do direito à saúde do trabalhador: uma análise comparativa dos sistemas jurídicos brasileiro e espanhol. São Paulo: LTr, 2013.

YUNUS, Muhamed. Um mundo sem pobreza: a empresa social e o futuro do capitalismo. Tradução Juliana A. Saad e Henrique Amat Rêgo Monteiro. São Paulo: Ática, 2008. 